\title{
Towards Better Joint Work: Reflections on Partnership Effectiveness
}

\author{
Gerard Ralphs and Isabella E. Wagner
}

\begin{abstract}
This chapter reflects on the issue of the "health" of cooperative projects, which it defines as the quality of the partnering relationships that underpin project-based networks. Recognising the recent proliferation of project-based networks in bi-regional research and innovation cooperation, and the challenges facing these networks, the authors propose practical applications drawing from their experiences as partners from Africa and Europe. These applications cover issues such as harmonising interests, acknowledging resources and addressing cultural specificities. They also argue that using evaluative approaches, such as partnership learning, is crucial for the partners' ability to handle success and failure.
\end{abstract}

Keywords Practitioners - Partnering processes - Partnership effectiveness $\bullet$ Good practices $\bullet$ Hidden interests $\bullet$ Cultural specificities $\bullet$ Personal identities • Power asymmetries • Informal networks • Interest-based negotiation

G. Ralphs $(\bowtie)$

Human Sciences Research Council, Cape Town, South Africa

I.E. Wagner

Centre for Social Innovation, Vienna, Austria

(C) The Author(s) 2018

A. Cherry et al. (eds.), Africa-Europe Research and Innovation

Cooperation, https://doi.org/10.1007/978-3-319-69929-5_7 


\section{INTRODUCTION $^{1}$}

Africa-Europe cooperation in research and innovation can be characterised as a large and complex web of relationships, in which political, institutional and individual interests are at play. At one level, these relationships take shape in formal political agreements or project-based networks, while at another level they are realised in less formal, collaborative and interpersonal interactions, forged between professionals or institutions over time. Irrespective of their degree of formality, dynamism or purpose, these relationships are both constitutive and generative of the cooperation and are therefore essential to garnering an understanding of its present character and future potential. In this chapter, we are less concerned with the nature of the larger-scale science partnership between Africa and Europe explored in the previous chapters. Rather, we focus on the relationships between individuals and their organisations working within project-based networks, and argue that much more attention needs to be paid, by project members, their leaders and funders, to the partnering processes in and through which these working relationships are developed.

Admittedly, this is not a novel topic within the domains of research and innovation management and policy. In recent decades, we have seen a proliferation of toolkits to help researchers and institutions collaborating across borders to work together more effectively (see, e.g. OECD 2011; KPFE 2012). While these toolkits contain important values or principles to inform partnering processes, only recently have some of them started to provide practicable advice for how the challenges of partnering processes can be mitigated in a bi-regional context (see Chap. 6; see also, e.g. COHRED 2016). Thus, building from our understanding of the field as well as from our subjective experiences as collaborators from Africa and Europe in a multilateral network (a research and innovation cooperation support project spanning a five-year period), we offer our analysis as well as four actionable suggestions to the field of professional practice. Moreover, we suggest that more research is needed to better understand not simply what makes Africa-Europe partnerships in research and innovation work, but also what-looking into the future-will make them work well.

\section{Why We Need Better Partnering, Now}

As the previous chapters in this book have shown, collaborative research and innovation has become a more noticeable feature of Africa-Europe relations. Burgeoning collaborations operate at different speeds and are 
characterised by varying compositions, approaches and degrees of formality/informality. Some take form in project-based consortia, which come to an end when their funding cycles are completed. Others take form in bilateral or multilateral cooperative agreements between countries, such as the complex calculus of agreements underpinning the European Developing Countries Clinical Trials Partnership (EDCTP) or the Square Kilometre Array, which invariably involve a wide range of institutional actors and outputs and extend over many years. Others, yet, are interinstitutional arrangements specifying a broad range of continuous cooperative activities, such as student and staff exchanges or the sharing of research infrastructures; or even individual collaborative relationships that span entire careers. Many of these relationships overlap and intersect with each other and with a web of larger-scale initiatives addressing pressing challenges such as climate change, food insecurity and public health crises (European Union 2015). Whatever their catalysts, geometries or levels of engagement, partnerships are a crucial unit of analysis for understanding but also preserving the overall shape and outputs of Africa-Europe research and innovation cooperation processes.

More specifically, multilateral funding programmes such as the European Union's (EU) Framework Programme (FP) and the African, Caribbean and Pacific (ACP) Science and Technology Programme, as well as many and various national funding programmes that exist between individual African and European countries, have supported numerous research and innovation project-based networks, spanning a wide range of thematic areas (for recent mappings of multilateral projects, see European Union 2010, 2014, 2015; European Communities 2009). Typical of these projectbased networks are a number of institutions or organisations that sign up to a non-returnable grant agreement, which binds a consortium to a set of contractual project deliverables that are aligned to priorities set out in a funding call (European Union 2014). Depending on their contractually defined roles and responsibilities, and their levels of in-kind contribution over and above the funders' investment, partners drawn from multiple country contexts work together in these networks at different levels of intensity and over a defined time horizon to deliver on their work plans. Given this specific bi-regional context, we use the terms "project-based network" and "partnership" interchangeably in this chapter. ${ }^{2}$

Studying the problems that arise when researchers and innovators from all over the world team up in project-based networks is fraught with historical, political and epistemic minefields, and can give rise to debate in 
which there are radically competing viewpoints. On the one hand, the language of colonialism or imperialism is sometimes invoked. For instance, in what could be considered a key paper in an emergent area of research partnership studies, Costello and Zumla (2000) describe a semi-colonial model of joint research work: "Some styles of research interaction pay little attention to ownership, sustainability and the development of national research capacity" (p. 827).

"Postal research," whereby Western researchers request colleagues in Africa to courier to them biological samples, is still practised, though less commonly than in the past. "Parachute research," whereby researchers travel to Africa or Asia for short periods of time and take back biological samples, is still relatively common. Results of both types of research are often published with minimal representation of African or Asian input. "Annexed sites" for field research, led and managed by expatriate staff, still predominate as the model for investment. (ibid.)

On the other hand, the language of research excellence is also used to justify the selection of partners in the context of competitive funding calls. For example, in a comment to a Research Africa news reporter in 2009, a European national researcher, remarking on the perceived quality of research interaction between institutions and researchers from Europe and Africa, was quoted as saying that "a majority of European institutions and their scientists consider that collaborative research with Africa is 'second hand' research" (Ralphs 2009). ${ }^{3}$

More recently, in the health research sector, Linda Nordling, a wellknown science policy journalist, has reported that the types of interaction described by Costello and Zumla seem to persist (Nordling 2015, p. 24). "Collaborations have proliferated in recent decades as international agencies have stepped up funding for health research in Africa," she writes (ibid.). "Yet African scientists say that they often feel stuck in positions such as data-collectors and laboratory technicians, with no realistic path to develop into leaders" (ibid.). In particular, Nordling investigated one very recent and widely publicised incident, in which researchers from the Kenya Medical Research Institute (KEMRI) are known to have won a court battle over allegations of institutional racism in relation to their UK counterparts in a health research partnership funded by the Wellcome Trust (see Nordling 2012, 2014a, b, 2015). There are other examples where the broader North-South partnership model has been publically 
brought into question by commentators (see, for instance Ishengoma 2011). However, the so-called KEMRI 6 incident is possibly a notable low for Africa-Europe research and innovation cooperation in recent decades, raising, as it does, the spectres of prejudice, structural inequality and power asymmetries.

From the above examples, it is evident that even though there are likely to be an equal number of positive experiences that could be reflected on, a few unhelpful characterisations appear to recur in the context of cooperation between researchers and innovators in Europe and Africa. One such characterisation is that Africa (often referred to in the singular, denoting a lack of diversity) is a "weak" partner, the partner in need of financial and technical support, or the partner whose capacities need to be built. The converse of this characterisation, of course, is that Europe is the financially and technically "strong" partner, the partner seeking research sites and data, and the partner who does the capacity building. Although resources differential and capacity asymmetries between African and European countries exist de facto, what is perhaps most telling is the extent to which these characterisations remain at odds with the political rhetoric contained in the Joint Africa-EU Strategy (JAES) (African Union \& European Union 2007). The vision of the JAES is of a very different model of cooperation between the Africa and Europe, principally cooperation based on, among others, "ownership" and "joint responsibility" (African Union \& European Union 2007, p. 2). In what ways could it be possible, then, for the unhelpful stereotypes to be replaced by a more constructive set of ideas and practices?

\section{Good Practices}

Studies on partnership in research and innovation have burgeoned in recent decades as collaborative models of knowledge production and technology development have emerged (The Royal Society 2011). Common to this growing body of research is an interest by scholars, funders and policymakers in the nature and outcomes of collaborative knowledge production and technology development, including its geopolitics, measurement, the cross-sectoral dimensions of collaboration, as well as the ways in which processes of working together can be improved, refined or adapted (e.g. European Union 2009, 2014; Breugelmans et al. 2015; ASSAF 2015). ${ }^{4}$ Responding directly to some of the challenge areas for partnerships identified at the beginning of this chapter, a rich body of literature 
began to emerge from the mid-1990s onwards concerning the factors that influence partnership effectiveness in research and innovation projects and programmes broadly, as well as in those initiatives involving developed and developing countries specifically (Table 7.1$).^{5}$

As shown above, several seemingly obvious aspects such as equality, joint agenda-setting and transparent communication are common to a number of these good practice frameworks. Both individually and taken together, these frameworks provide an important touchstone for prospective partners to consider in the pre-award or pre-partnership phase as well as during and after an agreement is concluded. Yet, perhaps one of the most compelling contributions to this discourse is from a 2011 OECD report, entitled Opportunities, challenges and good practices in international research cooperation between developed and developing countries, which argues:

There is not, nor should there be, a universal recipe for designing and conducting research collaborations. Each situation is, to some extent, unique, and must be treated as such. Nonetheless, a variety of generic descriptive parameters can be used to characterise collaborative programmes and projects, such that intelligent choices must be made regarding their optimal value on a case-by-case basis. This process of optimisation can be viewed as a search for balance between various relevant requirements, not all of which can be maximised at the same time. (OECD 2011 , p. 4; emphasis added $)^{6}$

The good practice frameworks and precepts mentioned above aim to promote a set of generic partnering principles within research and innovation. In the domains of professional development practice, the emergence of capacity development organisations, such as The Partnering Initiative, which trains partnership practitioners, or the emergence of initiatives such as the Council on Health Research for Development's Research Fairness Initiative (RFI) (see Chap. 6), which is developing a reporting mechanism for R\&I partnerships specifically, would suggest that the very mechanism of partnership has begun to be codified into a set of professional and organisational competencies. Indeed, many organisations working in research and innovation (universities, science councils, firms, government departments, non-profits) now have partnership offices or divisions to manage their engagement portfolios, or at least international offices for supporting partnership building. This degree of seriousness with which the partnership endeavour is being approached suggests that partnership as a modality of work and organisation requires considered and considerate organisational investment, strategy and even innovation. 
Table 7.1 Key success factors for transboundary research partnerships (Hollow 2011)

\begin{tabular}{|c|c|}
\hline Source & Key success factors \\
\hline Gaillard (1994) & $\begin{array}{l}\text { Strong mutual interest and both-sided benefits } \\
\text { Equal involvement into the proposal and all decisions } \\
\text { Joint decision on tools and instruments securing of their } \\
\text { installation, maintenance and repair } \\
\text { Include budget for a training component, if possible as part of a } \\
\text { formal degree programme to increase commitment } \\
\text { Salaries should be sufficient } \\
\text { Transparency on how budget is spent } \\
\text { Each participant organisation should include a substantial number } \\
\text { of researchers } \\
\text { Parties should meet regularly } \\
\text { Communication channels must be available to secure efficient } \\
\text { interaction between partners } \\
\text { Scientific papers should be written jointly, with the names of the } \\
\text { authors from both sides appearing on the published articles } \\
\text { Collaborative programmes should be evaluated on a regular basis }\end{array}$ \\
\hline $\begin{array}{l}\text { KPFE }(1998,2012, \\
2014)\end{array}$ & $\begin{array}{l}\text { Set the agenda together } \\
\text { Interact with stakeholders } \\
\text { Clarify responsibilities } \\
\text { Account to beneficiaries } \\
\text { Promote mutual learning } \\
\text { Enhance capacities } \\
\text { Share data and networks } \\
\text { Disseminate results } \\
\text { Pool profits and merits } \\
\text { Apply results } \\
\text { Secure outcomes }\end{array}$ \\
\hline $\begin{array}{l}\text { St-Pierre and Burley } \\
(2010) \text { - specifically } \\
\text { refers to donor } \\
\text { partnerships }^{\mathrm{a}}\end{array}$ & $\begin{array}{l}\text { Partnership roots } \\
\text { Positive interpersonal relations } \\
\text { Complementarity } \\
\text { Level of commitment } \\
\text { Risk management } \\
\text { Terms of engagement } \\
\text { Governance and decision making } \\
\text { Communication } \\
\text { Equal footing }\end{array}$ \\
\hline $\begin{array}{l}\text { European Union } \\
(2014)\end{array}$ & $\begin{array}{l}\text { Equitability in all aspects (including conception, budgets, } \\
\text { responsibilities, decision making, coordination and management) } \\
\text { Strong leadership, coordination and management and governance } \\
\text { Clear purpose, appropriate composition, division of } \\
\text { responsibilities and understanding of roles } \\
\text { Good communication, transparency and information exchange } \\
\text { Strong interpersonal relationships and mutual trust } \\
\text { Long-term investment }\end{array}$ \\
\hline
\end{tabular}

${ }^{\mathrm{a} E S S E N C E}$ on Health Research is a funder collaborative, consisting of donor partners working on health research for development (see http://www.who.int/tdr/partnerships/essence/members/en/, 2017) 


\section{Towards Better Joint Work: Four Key Issues FOR PARTNERship EfFectiveness}

In the context of a progressive and sustained interest in cooperation, our particular preoccupation in this chapter is with the issue of effectiveness in bi-regional partnerships/project-based networks in research and innovation. By effectiveness, we mean the extent to which the partnering activities support and enable the achievement of the goals of the partnership. As such we draw a distinction between the timely delivery of agreed project deliverables (project efficiency), on the one hand, and the "health" of the underlying network or partnership on the other hand (partnership effectiveness). ${ }^{7}$ Our suggestion here is that these are in fact parallel processes that require different levels of management expertise and participant contribution over the life cycle of a project. As Ralphs (2013) has argued elsewhere:

It is relatively easy for project participants to focus on the first process when evaluating their work, and there are numerous measures within project management for doing this. But success in these measures does not necessarily translate to a successful partnership. The partnership process often goes unevaluated, both because it is not predictable, and can be political. At an essential level, it comes down to difficult and likeable personalities, interaction across culture, gender and identity, institutional politics and interests, and the ability or inability to listen openly and intently—the stuff we don't often want or like to talk about.

Defined in this way, partnership effectiveness, we suggest, is a process and an outcome, requiring inputs from all partners in the stages encompassing the partnering cycle (The Partnering Initiative 2013). To state it differently, partners that sign up to a project grant agreement are not immediately effective. Effectiveness implies both a purposeful and a directed effort at becoming effective, which, once realised, we argue, is a desirable outcome for the partnerships itself as well as for its owners or benefactors. Reaching a "state" of partnership effectiveness, however, requires that partners work in particular ways towards their commonly defined objectives. So what are some of the key components that might help partners to become more effective on their partnership journeys? Clearly, from the above discussion, though there may be principles or factors underlying effective partnerships, there is no-one-size-fits-all approach to what constitutes an effective partnership in all instances. This means 
that the responsibility falls to partnership participants to determine what mechanisms to put in place to ensure their partnership works.

Building on the preceding discussions, we turn from a more contextual and theoretical analysis to our experiences as "African" and "European" partners in a bi-regional project-based network, CAAST-Net Plus, that was focussed on supporting research and innovation cooperation in relation to the global challenges of health, climate change and food security. At a glance, the partnership we were involved in might be seen to have met many if not all of the commonly-held criteria for an effective partnership as given in Table 7.1. This means that network participants were encouraged to conceive of and write the project together and, once approved to sign up to a non-binding consortium agreement that set out the terms of engagement between partners for the duration of the project. All of this pre-partnership documentation covered aspects such as decision making, governance, role definition and communication, and in its development, all partners were encouraged to contribute to creating an agreement fit to the particular network concerned. In addition, the network budgeted upfront for dedicated opportunities and resources for meeting in-person, for example, in the case of annual meetings, and for staff salaries to be paid for by the funder. Even though by regulation the project coordinator was required to be from an EU member state, an "Africa Region Coordinator" was appointed by the consortium to ensure appropriate voice and representation in the leadership of the network. To all intents and purposes, the network reflected the state-of-the-art in partnership theory and practice.

For all of its many positive contributions to bi-regional cooperation, what we encountered over time were four persistent challenge areas for the partnership. In the following section, we reflect on these challenges and share some suggestions for practical solutions to inspire future projectbased networks working on their partnering.

\section{Issue 1: The Problem of Hidden Interests}

Some of the key reasons for engaging in research and innovation partnership activities can be summarised in at least four drivers:

- Comparative advantage: Researchers and research organisations from different countries or regions bring to a particular topic a distinct advantage, knowledge or skill, such as access to research infrastructure, 
populations or research sites (particularly in the context of projects with a health-related, political support or astronomical function);

- Transnational issues: Many scientific or societal problems transcend national boundaries and therefore require multi-national (or increasingly global) responses (in this sense, the notion that science "knows no borders" applies);

- Scaling up: Through working together researchers and researcher organisations or indeed countries can achieve more than by working alone;

- Getting research to market: Involving the "private sector" is essential in ensuring knowledge is translated into products or services, and even profits (Laport 2017).

Politically correct as they are (and sound), these reasons and their concepts can in fact disguise the genuine interests that partners have in a particular project: funding, reputation, data, market share and so on. Put differently, each organisation involved in a partnership, however big or small, brings to the table a set of institutional or organisational, but also individual objectives or agendas (what we refer to as "interests"). After all, in the very definition of partnership, these objectives matter centrally to the partnership's design and should of course be made explicit in the negotiation and operation of the network. ${ }^{8}$ In our experience, however, interests that remained hidden or implicit result in a negative impact on the overall health of the cooperation.

Of course, it is difficult to know exactly the implicit interests of individuals, although in some instances these became evident in our experience. These hidden interests operated at an individual level, but also at the level of departments, institutions, organisations and whole countries. The key point to make is that we should try to be as honest as possible about implicit institutional interests and national interests, to set up projects that generate more effective partnerships because we know what to expect, and what responsibilities can be delegated. This needs to happen in the conceptualisation phase of a project.

PRACTICAL APPLICATION: Each partner should develop a statement of explicit and implicit institutional and individual interests in the conceptualisation phase of a project and an all-partner workshop on the convergence (and divergence) of partner interests in the context of the partnership's objectives should be undertaken. 
Theories of interest-based negotiation suggest that it is interests (not positions) that play the defining role in a negotiation (Hamann and Boulogne 2008). Interests are central to partnership environments, and yet can result in confusion if not handled with dexterity by the participants and managers of a partnership during its negotiation and its performance.

Reduced to the schematic level, for private sector organisations mandated by owners or shareholders, the drivers for participating in partnerships might be underpinned by profit or growth motives, by opportunities to access new markets, by Re D opportunities, or opportunities to expand their clientele. For government organisations mandated by taxpayers, the drivers for participating in multilateral networks may be determined by very specific national policy agendas and the results of those agendas for citizens. For policy research institutes or civil society organisations conducting research to influence policy, opportunities to conduct policy-relevant research and to shape policy discourses with that research may form part of their interest in joining a partnership.

As a solution to overcome the issue of diverging interests, we would in this practical application suggest working with the following approach (or derivation thereof): During the partnership's planning phase, every partner could be encouraged to fill out a survey aiming at identifying partners' interests in the context of the envisioned project endeavour. The institutional survey responses should then be merged to a statement of institutional interests shared with all partners. The results should then support structural decisions on planning tasks and responsibilities within the consortium. In a workshop back-to-back to the kick-off meeting the statement of interests should be discussed in plenary. Awareness of the existing interests should be raised and possible solutions for situations where interests could be conflicting should be developed.

\section{Issue 2: Personal Identities Matter in Professional Partnering Settings}

Networks invariably bring professionals in research and innovation together to jointly perform specific tasks under specific sets of conditions. These professionals are however in the first instance human beings with particular sets of identities that matter to them or that shape their interactions with others: gender, national, cultural and so on. It is easy to gloss over these identities in a collaboration context, under the guise of an assumed common professional environment and a project work plan. We want to explicitly state that, in our experience, these identities matter and may play a formative role in if/how individuals interact within a particular network, on a particular task, or in a group setting. Identities may, for example, determine if individuals feel comfortable to even speak or interact 
in particular ways in meetings or plenary settings, or even be able to do so without fear of embarrassment or reprisal. It is essential therefore that identities are not overlooked. By creating an awareness of identity in networks collaborators can work together more honestly and openly, and different identities then can be tapped as a resource for interpersonal relationship building rather than serve as an obstacle blocking effective collaboration. As a result, there needs to be recognition of interpersonal relationships and the need to relate productively at the interpersonal level. As Gaillard reminds us: "Personal friendships among the partners are also important to overcome many frustrations in the collaboration" (Gaillard 1994, p. 57).

PRACTICAL APPLICATION: Conduct a workshop on multiple identity working contexts at the beginning of a project. Questions that can be posed could include: What do the many linguistic, gender, cultural, national, or other identities that we bring to this project mean for the effectiveness of our joint work? In what ways could these identities hinder or encourage our work?

In science diplomacy settings, including multilateral project-based networks, there seems to be pretence that all collaborators are equally educated, all globally connected, and that there is no cultural barrier. For various reasons, however, the reality is that many individuals are not able to play a role or find a position in an agreement for this very reason. Often the cultural communication aspect in partnerships is ignored, even though language translation is provided.

In this practical application, we suggest conducting a workshop where the collaborators share their experiences from previous intercultural / transdisciplinary / multi-national cooperation environments and the main dos and don'ts of their working cultures. The workshop should be moderated by an experienced trainer. The main result of such a workshop would be the emerging of understanding and therefore trust amongst the project partners to support effective team-building.

\section{Issue 3: Money Is Not the Only Resource That Fuels}

\section{a Partnership}

The types of partnerships that we refer to in this chapter are project-based networks with a single major funding source. In projects supported, for example, under the EU's FP, it is obvious that funding is principally geared to European economic competitiveness objectives, that international 
research cooperation is one strategy to achieve this objective, and that coordinators of projects are from predominantly European organisations. Yet, in the bi-regional settings we worked in, there were many attempts made by the coordinator and the partners involved to create an equal environment for all partners. Despite these efforts, not all partners were able to assume the same amount of ownership and responsibility for project success. In our experience, for networks to function well, a number of resource pools are required in addition to finance, particularly in the kind of research support actions we performed. These are resources that all participants can bring to the table. They include in-kind contributions of time and research infrastructure, cost-saving possibilities for subcontracting services, experience and knowledge, networks and contacts, political buy-in, strategic geographic position and many more. To develop joint ownership of the project tasks and an understanding of who is contributing what kinds of resources to project success, we suggest conducting an ex-ante assessment by tracking the substance of what partners bring to the table.

\begin{abstract}
PRACTICAL APPLICATION: Perform an assessment of all available resources at the disposal of the partnership. Brainstorm this with partners and develop a comprehensive list. Then map the resources against the partnership's goal/purpose. Is there a mismatch? Does inequality in contribution mean the partnership is unequal?

This practical application could be done as a collaborative exercise of all partners in the planning phase of a partnership. Carefully map all the resources available to the partnership's common goal, no matter where resources originate, irrespective of the "amount" committed. Non-financial resources should be acknowledged as much as financial resources.
\end{abstract}

\title{
Issue 4: Success and Failure Matter to "Partnership LEARNING"
}

We can think of countless examples of partnering success and failure in our own experience. By success, we mean situations where the partnering activities enabled the achievement of the objectives of the partnership. By failure we mean situations where the partnering has resulted in gaps, confusion, missed opportunities or entire breakdown between partners. The details are not important. The point we wish to emphasise here is that both successes and failures need to be seen holistically within a framework 
of a partnership's experiential learning (learning by doing). Where a partnership can draw on its reflective capabilities to think through these instances and integrate the learning that arises, we think that it is in, and through these situations that a network begins to encounter and experience effectiveness. Practically speaking, by documenting institutional learning processes, the loss of experience in cases of high staff turnover can be mitigated.

\begin{abstract}
PRACTICAL APPLICATION: Establish explicit management structures for learning from success and failure.

There should be institutionalised processes for documenting and internally sharing lessons learned after major project milestones. The questions are relatively simple: What worked well? What didn't work at all? Why not? What should we keep, add or change? However, there are also implications for individual organisations which wish to do more partnering. These include the need to "formalise" a partnering function (Ralphs 2012), or to invest in the training of practitioners through organisations like The Partnering Initiative.
\end{abstract}

\title{
CONCLUSION
}

Given the growing number of good practices for partners to consider in the conduct of their collaborations, this chapter serves as a reminder that that there is no one-size-fits-all formula to achieving partnership effectiveness. Partners must take an active interest in ensuring their partnership health is maintained. Using our experience and learning as partners involved in biregional research and innovation cooperation between Africa and Europe, we present in this chapter suggestions for improving the sense of mutual ownership and mutual respect within project-based networks, and by extension the partnership effectiveness more broadly. These can be summarised as follows: (1) individual interests should be properly identified and acknowledged in a partnership's negotiations so as not to distort the project final results; (2) cultural specificities and communication should be openly discussed and explicitly integrated into project activities; (3) financial and non-financial resources should be mapped collaboratively during the planning of the project to recognise the full contributions that partners make; (4) institutional learning should become part of management programmes and be systematically conducted so as to enable partners to reflect on the successes and/or failures of their collaboration.

Just as research and innovation partnerships and the study of research collaboration have proliferated, so too has the practice of partnering 
evolved into a professional competence. These developments lead to a promising opportunity, which is that partnering theory and practice could be taken into account by institutions and organisations in Europe and Africa in the pre-award or conceptualisation stage as a way of addressing some of the challenges of asymmetry and dependence. Asymmetry in resources and capacities has, in part, fed harmful narratives about Africa and Europe that pervade the partnering process, making it challenging. These challenges need to be addressed, not only at the rhetorical level but also in practice, especially in the era of the JAES, which envisions a model of partnership based on equal ownership and joint responsibility. It is our sincere hope that we have contributed usefully to how the issues that hinder partnership effectiveness can be addressed, but also that we have opened a broader and fruitful discussion among actors in the field.

\section{Notes}

1. The authors acknowledge comments on earlier drafts of this chapter received from Dr Arne Tostensen of the Research Council of Norway and Dr Andrew Cherry of the Association of Commonwealth Universities, as well as and especially the chapter's blind peer reviewers. Gerard Ralphs acknowledges Research Africa and the Human Sciences Research Council, which supported the development of this chapter.

2. To the extent that we use the terms "research" and "innovation" or "research and innovation", a qualification is also in order. In recent years, specifically with the most recent FP, Horizon 2020, the issue of innovation has been coupled to research, reflecting a desire on the part of the programme for both knowledge production and knowledge utilisation. In this context, project-based networks are supported to deliver both research and innovation activities - and as such we use the broader formulation, "research and innovation", for the purpose of the discussion.

3. To be fair to the commentator in this context, he did add the following to the statement: "This is because there is a huge lack of communication about the 'frontier research' results already obtained with African partners" (ibid).

4. For an excellent but now slightly dated literature review, see Bradley (2007).

5. For a more review on the issue of partnership evaluation commissioned by the International Development Research Centre, see Hollow (2011).

6. Three areas in which such balance must be sought, according to the OECD (2011) report, include scientific achievement and development impact, inputs and contributions from the research partners, and top-down and bottom-up approaches. 
7. Gerard Ralphs is indebted to Suzanne Taylor and Lisa Burley of the International Development Research Centre for sharing the concept of partnership "health".

8. As Gaillard writes: "One of the determining conditions for successful collaboration is that the partners should be equal or at least complementary in many respects [...] [Collaboration can be successful] if the collaboration is based on a strong mutual interest and if both parties have something to gain from it" (1994, p. 57).

\section{REFERENCES}

African Union-European Union. (2007). The Africa-EU strategic partnership: A joint Africa-EU strategy. Brussels/Addis Ababa: Africa-EU Partnership.

ASSAF. (2015). Insights into South Africa's participation in the 7th Framework Programme for Research and Technological Development of the European Commission. Pretoria: Academy of Science of South Africa.

Bradley, M. (2007). North-South research partnerships: Challenges, responses and trends. Ottawa: International Development Research Centre.

Breugelmans J. G., Cardoso A. L. V., Gurney K. A., Makanga M. M., Mathewson S. B., Mgone C. S., \& Sheridan-Jones B. R. (2015). Bibliometric assessment of European and sub-Saharan African research output on poverty-related and neglected infectious diseases from 2003 to 2011. PLoS Neglected Tropical Diseases, 9(8). Available from: http://journals.plos.org/plosntds/ article?id=10.1371/journal.pntd.0003997. Accessed 16 May 2017.

COHRED. (2016). The research fairness initiative: Reporting for fairness in research partnerships for global health. Geneva: Council on Health Research for Development.

Costello, A., \& Zumla, A. (2000). Moving to research partnerships in developing countries. British Medical Journal, 321, 827-829.

European Communities. (2009). International cooperation with Africa in FP6: Project synopses. Luxembourg: Office for Official Publications of the European Communities.

European Union. (2009). Drivers of international collaboration in research: Final report. Luxembourg: Publications Office of the European Union.

European Union. (2010). The changing face of EU-African cooperation in science and technology: Past achievements and looking ahead to the future. Luxembourg: Publications Office of the European Union.

European Union. (2014). Mapping of best practice regional and multi-country cooperative STI initiatives between Africa and Europe: Identification of financial mechanisms 2008-2012. Luxembourg: Publications Office of the European Union. 
European Union. (2015). Investing in European success: EU-Africa cooperation in science, technology and innovation. Luxembourg: Publications Office of the European Union.

Gaillard, J. F. (1994). North-South research partnership: Is collaboration possible between unequal partners? Knowledge and Policy, 7(2), 31-63.

Hamann, R., \& Boulogne, F. (2008). Partnerships and cross-sector collaboration. In R. Hamann, S. Woolman, \& C. Sprague (Eds.), The business of sustainable development in Africa: Human rights, partnerships, alternative business models (pp. 54-82). Pretoria: UNISA Press.

Hollow, D. (2011). An academic review of the evaluation of partnerships in development. Ottawa: International Development Research Centre.

Ishengoma, J. M. (2011). North-South partnerships are not the answer. Available from: http://www.scidev.net/global/migration/opinion/north-south-partnerships-are-not-the-answer-1.html. Accessed 26 Apr 2016.

KPFE. (1998). Guidelines for research partnerships with developing countries: The 11 principles. Bern: Swiss Commission for Research Partnerships with Developing Countries.

KPFE. (2012). A guide for transboundary research partnerships: 11 principles and 7 questions (1st ed.). Bern: Swiss Commission for Research Partnerships with Developing Countries.

KPFE. (2014). A guide for transboundary research partnerships: 11 principles and 7 questions (2nd ed.). Bern: Swiss Commission for Research Partnerships with Developing Countries.

Laport, G. (2017). Time to move to an interest-driven Africa-EU political partnership. EDCPM. Available from: http://ecdpm.org/talking-points/time-interest-driven-africa-eu-political-partnership-part-two/?utm_source=ECDPM+Ne wsletters+List\&utm_campaign=0795947537-EMAIL_CAMPAIGN_2017_ 06_25\&utm_medium=email\&utm_term=0_f93a3dael4 -0795947537 388626221. Accessed 26 June 2017.

Nordling, L. (2012). African researchers sue flagship programme for discrimination. Nature, 487, 17-18. Available from: http://www.nature.com/news/ african-researchers-sue-flagship-programme-for-discrimination-1.10946. Accessed 16 May 2017.

Nordling, L. (2014a). Kenyan doctors win landmark discrimination case. Available from: http://www.nature.com/news/kenyan-doctors-win-landmark-discrimination-case-1.15594. Accessed 26 Apr [APRIL] 2016.

Nordling, L. (2014b). Lawsuit offers lessons for alliances. Available from: http:// www.scidev.net/sub-saharan-africa/cooperation/analysis-blog/africa-analysisalliances.html. Accessed 26 Apr [APRIL?] 2016.

Nordling, L. (2015). Research: Africa's fight for equality. Nature, 521, 24-25. Available from: http://www.nature.com/news/research-africa-s-fight-forequality-1.17486. Accessed 16 May 2017. 
OECD Global Science Forum. (2011). Opportunities, challenges and good practices in international research cooperation between developed and developing countries. Paris: Organisation Economic Co-operation and Development.

Ralphs, G. (2009). Africa-Europe research co-operation on the move. Available from: https://www.research-professional.com. Accessed 26 Apr [APRIL] 2016.

Ralphs, G. (2012). Partnership and organisational capacity: An exploratory study of the partnering function in research organisations in East and Southern Africa (Unpublished research report).

Ralphs, G. (2013). Improving partnerships. Available from: https://www.researchprofessional.com. Accessed 26 Apr 2016.

St-Pierre, D., \& Burley, L. (2010). Factors influencing donor partnership effectiveness. Foundation Review, 1(4), 53-61.

The Partnering Initiative. (2013). The partnering cycle. London: The Partnering Initiative.

The Royal Society. (2011). Knowledge, networks and nations: Global scientific collaboration in the 21st century. London: The Royal Society.

Open Access This chapter is licensed under the terms of the Creative Commons Attribution 4.0 International License (http://creativecommons.org/licenses/ by $/ 4.0 /$ ), which permits use, sharing, adaptation, distribution and reproduction in any medium or format, as long as you give appropriate credit to the original author(s) and the source, provide a link to the Creative Commons license and indicate if changes were made.

The images or other third party material in this chapter are included in the chapter's Creative Commons license, unless indicated otherwise in a credit line to the material. If material is not included in the chapter's Creative Commons license and your intended use is not permitted by statutory regulation or exceeds the permitted use, you will need to obtain permission directly from the copyright holder.

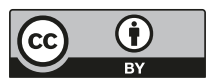

